\title{
A Study on the Relationship between Nutrition Status and Physical Fitness of School Boys.
}

\author{
* Dr. Saikot Chatterjee ** Sri, Jahirul Biswas., *** Dr. Samir Ranjan Adhikary. \\ * Asst. Prof. Department of Physical Education, University of Kalyani. West Bengal. \\ ** Student M.P.Ed. $4^{\text {th }}$ Sem. University of Kalyani. *** Asst. Prof. Sachidananda College of Education,
} Simurali. West Bengal.

\begin{abstract}
Nutritional status during school age is a major determinant of nutritional and health status in adult life. Many studies showed that under nutrition and anaemia had an adverse impact on performance and consequently led to reduction in wages for persons employed in manual labour.

The past three decades have witnessed the emergence of over nutrition as a problem in school-age children in developed countries and in affluent urban segments in developing countries. The main determinants of performance are physical fitness and skill. Longitudinal studies have shown that the lifestyle and physical fitness during childhood and adolescence were major determinants of lifestyle, physical fitness and freedom from non-communicable diseases in adult life.

According to the knowledge gathered from available literature it was somehow clear that numerous studies have been conducted to determine the relationship between body composition and body type on motor performance, but research in the area directly concerned with determining the relationship between nutrition status and physical fitness components is rare so the author strived to ponder on the fact how physical performance gets affected by the nutrition status and thus selected the problem "A STUDY ON THE REALATIONSHIP BETWEEN NUTRITION STATUS AND PHYSICAL FITNESS OF SCHOOL BOYS".

PURPOSE OF THE STUDY: The main purpose of the study is to find out if there is any relationship between Nutrition status and Physical fitness of school going boys.A total of 44 boys within the age group of 8-9 years were selected from the Puratan Pitamberpur Primary School and Chapra Primary School. The subjects were selected randomly with the help of drawing lots for the present study. The subjects were selected from rural areas of West Bengal. The rural area subjects The life style including food habits, made of transport, nature of recreation and amusement were also considered.

AAHPERD youth fitness battery was used for assessment of motor performance and weight for age was adopted as the measure of nutrition status. Mean SD. were computed to determine descriptive statistics and further ANOVA was worked out for analysis of variance. From data analysis it appears that there was no. significant difference between the different nutrition status groups with respect to motor performance variables except the variable sit up which shows significant difference at 0.02 level. Though in the cases of $50 \mathrm{mt}$ dash, and $600 \mathrm{mts}$. run the $F$ values are near to significant.

From the data analysis it can also be inferred that the motor performance variables like $50 \mathrm{mts}$. dash, $600 \mathrm{mts}$. run \& walk, and sit up are influenced by the nutrition status of an individual to the greater extent or in other way it can be deduced that the fitness variable like sit up, $50 \mathrm{mts}$. dash and $600 \mathrm{mts}$. run are determinants of nutrition status of an individual.
\end{abstract}

Key words: Nutrition Status, Physical Fitness, School Boys.

\section{Introduction}

Nutritional status during school age is a major determinant of nutritional and health status in adult life. Globally, including in India, health hazards associated with under nutrition and micronutrient deficiencies remain major public health problems. In the second half of the previous century, the adverse effects of under nutrition and anaemia on physical performance were extensively investigated in adults. Many studies showed that under nutrition and anaemia had an adverse impact on performance and consequently led to reduction in wages for persons employed in manual labour.

The past three decades have witnessed the emergence of over nutrition as a problem in school-age children in developed countries and in affluent urban segments in developing countries. In developed countries, the consumption of high-calorie food and the increasingly sedentary lifestyle have been implicated as the major factors responsible for the rising obesity rates. In India there has not been a substantial increase in energy intake among children except those in urban affluent families. The increasing obesity rates in children are attributable mainly to the substantial reduction in physical activity in the form of household chores, methods of commuting (the use of mortised conveyances instead of walking or cycling) and methods of recreation (with computer games and TV watching having replaced physical play) over the past two decades. Overweight children are at 
higher risk of becoming over nourished adults and thereby incurring a higher risk of developing noncommunicable diseases.

Physical performance is defined as the ability to perform a physical task or sport at a desired level

The main determinants of performance are physical fitness and skill. Longitudinal studies have shown that the lifestyle and physical fitness during childhood and adolescence were major determinants of lifestyle, physical fitness and freedom from non-communicable diseases in adult life.

According to the knowledge gathered from available literature it was somehow clear that several research studies have been conducted on the relationship between BMI and physical fitness components. Numerous studies have been conducted to determine the relationship between body composition and body type on motor performance, but research in the area directly concerned with determining the relationship between nutrition status and physical fitness components is rare so the author strived to ponder on the fact how physical performance gets affected by the nutrition status and thus selected the problem "A STUDY ON THE REALATIONSHIP BETWEEN NUTRITION STATUS AND PHYSICAL FITNESS OF SCHOOL BOYS".

PURPOSE OF THE STUDY: The main purpose of the study is to find out if there is any relationship between Nutrition status and Physical fitness of school going boys. To identify the health related fitness components. To find out the influence of different nutrition status on the various motor quality variables.

Present study was conducted to know the status of relationship between nutrition status and selected motor performance variables for primary school boys.

A total of 44 boys within the age group of 8-9 years. The subjects were selected randomly with the help of drawing lots for the present study. The subjects were selected from rural areas of West Bengal. The rural area subjects were selected from the Puratan Pitamberpur Primary School and Chapra Primary School. The life style including food habits, made of transport, nature of recreation and amusement were also considered.

Data were taken from a single school in a day and the total time taken were near about 3-4 hours daily within 10 days total data were collected. It was collected in the late winter season (March - April) and $30^{\circ} \mathrm{C}-35^{\circ} \mathrm{C}$ (Maxi) humidity was very low.

AAHPERD youth fitness battery was used for assessment of motor performance and weight for age was adopted as the measure of nutrition status. Mean SD. were computed to determine descriptive statistics and further ANOVA was worked out for analysis of variance. From data analysis it appears that There was no. significant difference between the different nutrition status groups with respect to motor performance variables except the variable sit up which shows significant difference at 0.02 level. though in the cases of $50 \mathrm{mt}$ dash, and $600 \mathrm{mts}$. run the $\mathrm{F}$ values are near to significant.

From the data analysis it can also be inferred that the motor performance variables like $50 \mathrm{mts}$. dash, $600 \mathrm{mts}$. run \& walk, and sit up are influenced by the nutrition status of an individual to the greater extent or in other way it can be deduced that the fitness variable like sit up, $50 \mathrm{mts}$. dash and $600 \mathrm{mts}$. run are determinants of nutrition status of an individual.

\section{Gomez' Classification}

Gomez' classification is based on weight retardation which was used to categorize the children on the basis of nutrition status. It locates the child on the basis of his or her weight in comparison with a normal child of the same age.

Formula for weight percentage calculation:

$$
\text { Weight for age }(\%)=\frac{\text { weight of the child }}{\begin{array}{l}
\text { weight of a normal } \\
\text { child of same age }
\end{array}} \times 100
$$

\begin{tabular}{|l|l|}
\hline Grade & Weight-for-age \\
\hline Normal nutritional status & Between $90 \& 110 \%$ \\
\hline $1^{\text {st } *}$, mild malnutrition & Between 75 and $89 \%$ \\
\hline $2^{\text {nd } *}$, moderate malnutrition & Between 60 and $74 \%$ \\
\hline $3^{\text {rd } *}$, severe malnutrition & Under $60 \%$ \\
\hline
\end{tabular}

First of all the investigator like to mention that according to the nature of the study the subjects were categorized into three different groups Mild, Moderate and Normal, on the basis of their Nutrition Status i.e. weight for age. The formula and the norms of which has been presented if chapter III earlier. 
Table-1. Shows the Mean and S.D. of height and weight.

\begin{tabular}{|l|l|l|l|l|}
\hline & & N & Mean & Std. Dev \\
\hline HEIGHT $(\mathrm{cm})$ & Nutrition Status & & & \\
\cline { 2 - 5 } & Mild & 24 & 126.46 & 6.318 \\
\cline { 2 - 5 } & Moderate & 12 & 122.58 & 5.551 \\
\cline { 2 - 5 } & Normal & 18 & 133.67 & 3.498 \\
\cline { 2 - 5 } & Total & 54 & 128.00 & 6.802 \\
\hline WEIGHT(kg) & Mild & 24 & 21.67 & 2.057 \\
\cline { 2 - 5 } & Moderate & 12 & 19.25 & 1.055 \\
\cline { 2 - 5 } & Normal & 18 & 28.00 & 4.446 \\
\cline { 2 - 5 } & Total & 54 & 23.24 & 4.564 \\
\hline
\end{tabular}

According to the table the mean height of the three different Nutrition Status categories of boys i.e. Mild, Moderate, and Normal are 126.46, 122.58 and $133.67 \mathrm{cms}$. And S.D. are 6.318, 5.551, and $3.498 \mathrm{cms}$. The mean weight for the same three groups is $21.67,19.25$ and 28.00. K.G. and their S.D. are 2.057, 1.055 and 4.446. The mean for $50 \mathrm{mt}$. dash are 9.757, 9.359 and 9.140 secs. And S.D.'s are 1.188, .6101 and .3742. Mean scores for shuttle run are 12.54, 12.32, 12.54 and their corresponding S.D.'s are $.852, .603$ and .593. The mean scores for pull up are 4.50, 6.17, and 3.67 and the S.D.'s are 2.94, 4.06 and 1.74. The mean scores for the fitness test sit up are 17.13, 22.67, 26.00 and the S.D.'s are 9.76, 9.83 and 10.18. The mean scores for Standing Broad Jump are 1.29, 1.33, and 1.35 and their S.D.'s are $.164, .170$ and .170. The Mean scores for $600 \mathrm{mts}$. Run and walk are $175.63,173.75$ and 168.33 and their corresponding S.D.'s are 11.72, 11.16 and 6.30 respectively.

\section{With Respect To Height And Weight:}

From the table it appears that in both the cases of height and body weight the children with normal nutrition status are better that their mild malnutrition counterpart and similarly the children with mild malnutrition are better in comparison to the children with moderate malnutrition. The table also depicts some differences with respect to motor performance variables scores and for which ANOVA was computed to locate the degree of difference between the means and further multiple comparison was also executed to find out the inter difference between the groups.

Table 2. Shows the mean and S.D for the motor performance variables.

\begin{tabular}{|c|c|c|c|c|}
\hline \multirow[t]{4}{*}{$50 \mathrm{~m}(\mathrm{sec})$} & Mild & 24 & 9.757 & 1.1883 \\
\hline & Moderate & 12 & 9.359 & .6101 \\
\hline & Normal & 18 & 9.140 & .3742 \\
\hline & Total & 54 & 9.463 & .9011 \\
\hline \multirow[t]{4}{*}{ SHUTTLE RUN(sec) } & Mild & 24 & 12.5408 & .85292 \\
\hline & Moderate & 12 & 12.3233 & .60343 \\
\hline & Normal & 18 & 12.5433 & .59375 \\
\hline & Total & 54 & 12.4933 & .71607 \\
\hline \multirow[t]{4}{*}{ PULL UP } & Mild & 24 & 4.50 & 2.949 \\
\hline & Moderate & 12 & 6.17 & 4.064 \\
\hline & Normal & 18 & 3.67 & 1.749 \\
\hline & Total & 54 & 4.59 & 3.006 \\
\hline \multirow[t]{4}{*}{ SIT UP } & Mild & 24 & 17.13 & 9.768 \\
\hline & Moderate & 12 & 22.67 & 9.838 \\
\hline & Normal & 18 & 26.00 & 10.186 \\
\hline & Total & 54 & 21.31 & 10.517 \\
\hline \multirow[t]{4}{*}{ S.B.J(m) } & Mild & 24 & 1.295 & .1642 \\
\hline & Moderate & 12 & 1.335 & .1848 \\
\hline & Normal & 18 & 1.357 & .1706 \\
\hline & Total & 54 & 1.324 & .1700 \\
\hline \multirow[t]{4}{*}{$600 \mathrm{mts}$} & Mild & 24 & 175.63 & 11.728 \\
\hline & Moderate & 12 & 173.75 & 11.169 \\
\hline & Normal & 18 & 168.33 & 6.306 \\
\hline & Total & 54 & 172.78 & 10.437 \\
\hline
\end{tabular}


With respect to motor performance variables: According to table no. 2 . The mean value in $50 \mathrm{mt}$. is lowest for boys with normal nutrition, lower for boys with mild malnutrition and highest for boys with moderate malnutrition. Similarly from the table value it appears that the mean value in case of $600 \mathrm{mts}$. run and walk performance of the boys with normal nutrition status is lower than those of the boys with mild and moderate nutrition status. The result is same incase of

Standing broad jump and sit up i.e. in both of these cases the means values for the boys with normal nutrition are higher than those of the boys with mild malnutrition and values are higher for boys with mild malnutrition than those of the boys with moderate malnutrition. The scenario is somehow different in case of the variables shuttle run and pull up. In case of pull up the mean value for boys with moderate malnutrition shows highest value in comparison to those of mild and normal nutrition status. While in case of shuttle run the mean value are nearly equal for boys with mild and normal nutrition but for boys with moderate malnutrition the value is lower.

Table 3. shows the analysis of variance for motor performance variables.

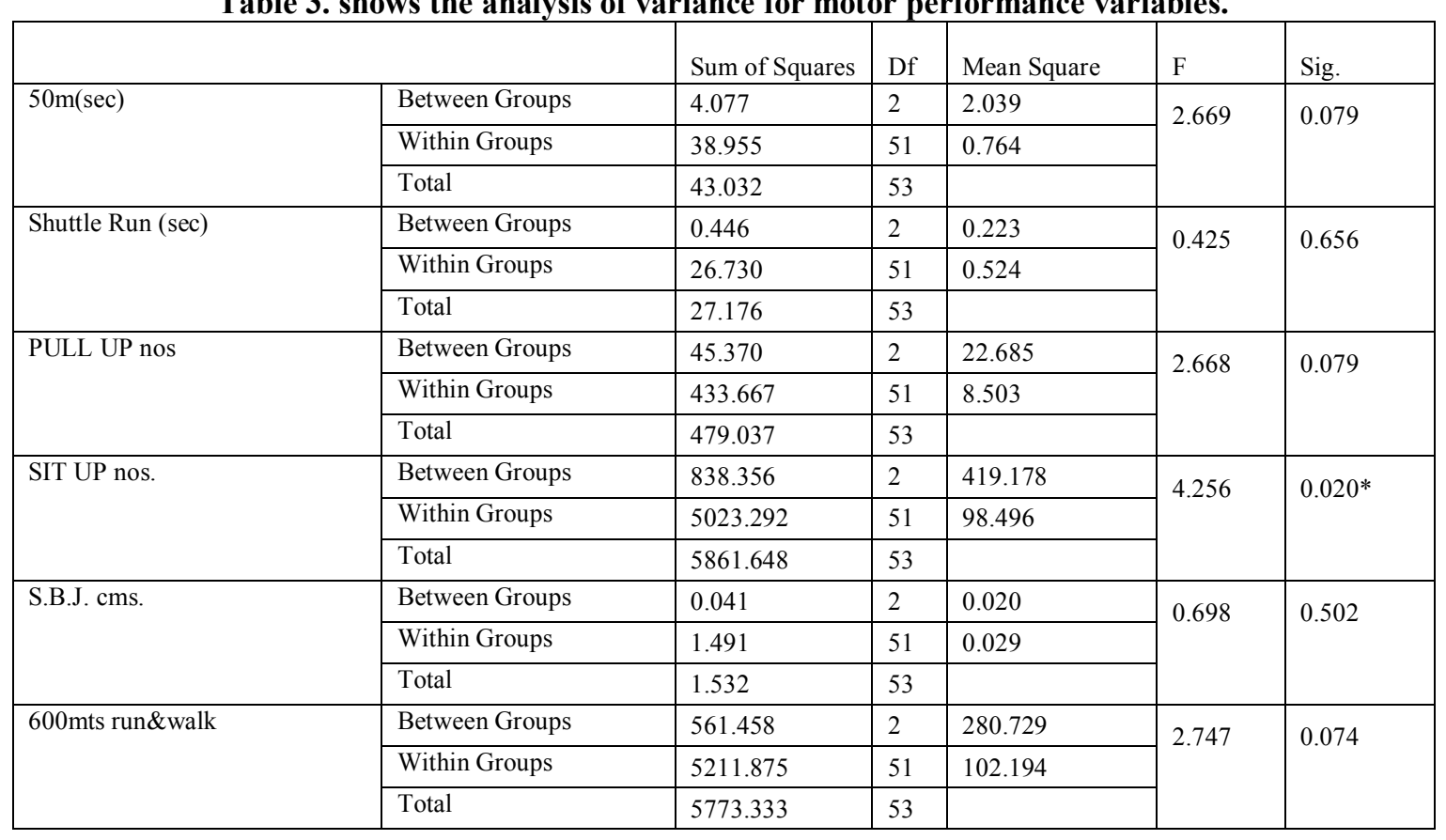

The F scores presented in table no.3 reveals that there was no. significant difference between the different nutrition status groups with respect to motor performance variables except the variable sit up which shows significant difference at 0.02 levels. Though in the cases of $50 \mathrm{mt}$ dash, and $600 \mathrm{mts}$. run the F values are near to significant.

In this regard the following research findings may be cited.

Sarah et al. (2003) reached to the conclusion in his study on adolescent boys that on several measures underweight boys were less likely to be physically active that boys of normal weight.

Taylor et al. (1991) investigate in a sample of 93 high adiposity and 93 low adiposity children ages 8 to 13 with cardiovascular fitness as the dependent variable, relationships with habitual level of physical activity, age gender and body mass index (BMI). For the high adiposity sample, physical activity score, age, BMI were significant and the overall model was significant $(\mathrm{P}$, less than 0.001$)$. In the low adiposity sample they were significantly related to cardiovascular fitness but the overall model was not significant ( $\mathrm{P}$, less that 0.35 ) physical activity score thus was a significant predictor of cardiovascular fitness among the high adiposity children but not the low adiposity children.

Thus it may be inferred that the findings of the present study are in close proximity with the findings of some leading researchers

Further multiple comparisons (presented in table no. 4)were computed to find inter group difference. The result presented in the table shows significant difference between mild and normal nutritional status boys in $50 \mathrm{mts}$. dash. In sit up performance significant difference was established between boys of mild and normal nutrition status. Significant difference was also established between boys of mild and normal nutrition status with respect to performance in $600 \mathrm{mts}$. run\& walk. 
A Study on the Relationship between Nutrition Status and Physical Fitness of School Boys.

Table. 4. Multiple comparisons between various groups.

\begin{tabular}{|c|c|c|c|c|c|}
\hline \multicolumn{6}{|l|}{ Dependent Variable } \\
\hline & (I) $\mathrm{NS}$ & (J) NS & Mean Difference (I-J) & Std. Error & Sig. \\
\hline \multirow[t]{3}{*}{$50 \mathrm{~m}(\mathrm{sec})$} & Mild & Moderate & .3975 & .3090 & 0.204 \\
\hline & Mild & Normal & $.6167(*)$ & .2725 & 0.028 \\
\hline & Moderate & Normal & .2192 & .3257 & 0.504 \\
\hline \multirow[t]{3}{*}{ SHUTTLE RUN(sec) } & Mild & Moderate & .21750 & .25596 & 0.399 \\
\hline & Mild & Normal & -.00250 & .22574 & 0.991 \\
\hline & Moderate & Normal & -.22000 & .26981 & 0.419 \\
\hline \multirow[t]{3}{*}{ PULL UP } & Mild & Moderate & -1.667 & 1.031 & 0.112 \\
\hline & Mild & Normal & .833 & .909 & 0.364 \\
\hline & Moderate & Normal & $2.500(*)$ & 1.087 & 0.026 \\
\hline \multirow[t]{3}{*}{ SIT UP } & Mild & Moderate & -5.542 & 3.509 & 0.120 \\
\hline & Mild & Normal & $-8.875(*)$ & 3.095 & 0.006 \\
\hline & Moderate & Normal & -3.333 & 3.699 & 0.372 \\
\hline \multirow[t]{3}{*}{ S.B.J $(\mathrm{m})$} & Mild & Moderate & -.0400 & .0604 & 0.511 \\
\hline & Mild & Normal & -.0617 & .0533 & 0.253 \\
\hline & Moderate & Normal & -.0217 & .0637 & 0.735 \\
\hline \multirow[t]{3}{*}{$600 \mathrm{mts}$} & Mild & Moderate & 1.875 & 3.574 & .602 \\
\hline & Mild & Normal & $7.292(*)$ & 3.152 & .025 \\
\hline & Moderate & Normal & 5.417 & 3.767 & .157 \\
\hline
\end{tabular}

* The mean difference is significant at the .05 level.

From the data analysis it can also be inferred that the motor performance variables like $50 \mathrm{mts}$. dash, $600 \mathrm{mts}$. run \& walk, and sit up are influenced by the nutrition status of an individual to the greater extent or in other way it can be deduced that the fitness variable like sit up, $50 \mathrm{mts}$. dash and $600 \mathrm{mts}$. run are determinants of nutrition status of an individual.

\section{Conclusion}

The findings of the present study lead to the following conclusions:

There was no. significant difference between the different nutrition status groups with respect to motor performance variables except the variable sit up which shows significant difference at 0.02 level. though in the cases of $50 \mathrm{mt}$ dash, and $600 \mathrm{mts}$. run the $\mathrm{F}$ values are near to significant.

From the data analysis it can also be inferred that the motor performance variables like $50 \mathrm{mts}$. dash, $600 \mathrm{mts}$. run \& walk, and sit up are influenced by the nutrition status of an individual to the greater extent or in other way it can be deduced that the fitness variable like sit up, $50 \mathrm{mts}$. dash and $600 \mathrm{mts}$. run are determinants of nutrition status of an individual.

\section{References:}

[1]. Collins, Steve (1996). "Using Middle Upper Arm Circumference to Assess Severe Adult Malnutrition During Famine." Journal of the American Medical Association 276(5):391-395.

[2]. Kiernan, M. (2000). "Identifying Patients for Weight-Loss Treatment: An Empirical Evaluation of the NHLBI Obesity Education Initiative Expert Panel Treatment Recommendations." Archives of Internal Medicine 160:2169-2176.

[3]. Kuczmarski, Marie Fanelli (2001). "Effects of Age on Validity of Self-Reported Height, Weight, and Body Mass Index: Findings from the Third National Health and Nutrition Survey, 1988-1994." Journal of the American Dietetic Association 101(1):28-34.

[4]. $\quad$ Landi, F. (2000). "Body Mass Index and Mortality Among Hospitalized Patients." Archives of Internal Medicine 160:2641-2644.

[5]. Maskarinec, G. (2000). "Dietary Patterns Are Associated with Body Mass Index in Multiethnic Women." Journal of Nutrition 130:3068-3072.

[6]. Maynard, L. M. (2001). "Childhood Body Composition in Relation to Body Mass Index." Pediatrics 107:344-350.

[7]. Pike, Ruth, and Brown, Myrtle L. (1984). Nutrition, An Integrated Approach. New York: John Wiley.

[8]. Seidel, J. C. (2001). "Report from a CDC Prevention Workshop on Use of Adult Anthropometry for Public Health and Primary Health Care." American Journal of Clinical Nutrition 73:123-126. 